\title{
Intimate partner violence and anxiety disorders in pregnancy: the importance of vocational training of the nursing staff in facing them ${ }^{1}$
}

\author{
Mariana de Oliveira Fonseca-Machado² \\ Juliana Cristina dos Santos Monteiro ${ }^{3}$ \\ Vanderlei José Haas ${ }^{4}$ \\ Ana Cristina Freitas de Vilhena Abrão ${ }^{5}$ \\ Flávia Gomes-Sponholz ${ }^{6}$
}

\begin{abstract}
Objective: to identify the relationship between posttraumatic stress disorder, trait and state anxiety, and intimate partner violence during pregnancy. Method: observational, cross-sectional study developed with 358 pregnant women. The Posttraumatic Stress Disorder Checklist - Civilian Version was used, as well as the State-Trait Anxiety Inventory and an adapted version of the instrument used in the World Health Organization Multi-country Study on Women's Health and Domestic Violence. Results: after adjusting to the multiple logistic regression model, intimate partner violence, occurred during pregnancy, was associated with the indication of posttraumatic stress disorder. The adjusted multiple linear regression models showed that the victims of violence, in the current pregnancy, had higher symptom scores of trait and state anxiety than non-victims. Conclusion: recognizing the intimate partner violence as a clinically relevant and identifiable risk factor for the occurrence of anxiety disorders during pregnancy can be a first step in the prevention thereof.
\end{abstract}

Descriptors: Spouse Abuse; Anxiety; Stress Disorders, Post-Traumatic; Pregnancy; Nursing; Public Health.

\footnotetext{
1 Paper extracted from doctoral dissertation "Violence during pregnancy and the mental health of women victims of their partners", presented to Escola de Enfermagem de Ribeirão Preto, Universidade de São Paulo, PAHO/WHO Collaborating Centre for Nursing Research Development, Ribeirão Preto, SP, Brazil. Supported by Fundação de Amparo à Pesquisa do Estado de São Paulo (FAPESP), Brazil, process \# 2012/06037-0.

2 PhD, Adjunct Professor, Departamento de Enfermagem, Universidade Federal de São Carlos, São Carlos, SP, Brazil.

3 PhD, Professor, Escola de Enfermagem de Ribeirão Preto, Universidade de São Paulo, PAHO/WHO Collaborating Centre for Nursing Research Development, Ribeirão Preto, SP, Brazil.

${ }^{4} \mathrm{PhD}$, Researcher, Universidade Federal do Triângulo Mineiro, Uberaba, MG, Brazil.

${ }^{5} \mathrm{PhD}$, Adjunct Professor, Escola Paulista de Enfermagem, Universidade Federal de São Paulo, São Paulo, SP, Brazil.

${ }^{6} \mathrm{PhD}$, Associate Professor, Escola de Enfermagem de Ribeirão Preto, Universidade de São Paulo, PAHO/WHO Collaborating Centre for Nursing Research Development, Ribeirão Preto, SP, Brazil.
}

Corresponding Author:

Mariana de Oliveira Fonseca-Machado

Universidade Federal de São Carlos. Departamento de Enfermagem

Rod. Washington Luís, Km 235. Caixa Postal 676

Bairro: Monjolinho

CEP: 13565-905, São Carlos, SP, Brasil

E-mail: mafonseca.machado@gmail.com
Copyright $\odot 2015$ Revista Latino-Americana de Enfermagem This is an Open Access article distributed under the terms of the Creative Commons Attribution Non-Commercial License (CC BY-NC).

This license lets others distribute, remix, tweak, and build upon your work non-commercially, and although their new works must also acknowledge you and be non-commercial, they don't have to license their derivative works on the same terms. 


\section{Introduction}

Violence against women is one of the main forms of violation of human rights to life and health. It is a worldwide public health problem, not determined by social class, ethnicity, religion, age, marital status, education, or sexual orientation, which requires efforts from various spheres for prevention and intervention. In this context, Intimate Partner Violence (IPV) is characterized by acts of physical aggression, sexual coercion, psychological abuse, and controlling behaviors, perpetrated by current or previous partners ${ }^{(1)}$.

The IPV situation is more prevalent among women in reproductive age and can occur during pregnancy, which makes it particularly worrying because of the adverse effects on the health of the mother, of the fetus and, subsequently, of the child. Pregnant women, compared to non-pregnant women, are at higher risk of violence by the partner, since, in general, they are involved in an intimate relationship ${ }^{(2)}$. The prevalence of such violence, during pregnancy, differs among populations worldwide and the rates tend to be higher in Latin American countries $^{(3)}$, with rates ranging from 3.0 to $34.5 \%$ for sexual violence, 2.5 to $38.7 \%$ for physical violence, and 13.0 to $44.0 \%$ for psychological violence. These data are consistent with the idea that IPV is more common in populations where gender inequality is sustained by social and cultural norms and where punishment of women is accepted as the partner's prerogative ${ }^{(4)}$.

Thus, the pregnancy-childbirth cycle, often seen as a time of emotional well-being, can, also, represent a moment of stress. Stressful situations trigger emotional changes or mental disorders, which are characterized as the most common health problems associated with pregnancy ${ }^{(5)}$. Violence perpetrated by an intimate partner is considered a stressor for many women and contributes to the occurrence of anxiety disorders during pregnancy, such as trait and state anxiety and Posttraumatic Stress Disorder (PTSD) ${ }^{(6-7)}$, which are associated with adverse effects to the fetus, the child, and the woman.

Anxiety disorders are the most common mental disorders in the general population and occur in all ages, being common in pregnancy and childbirth, a moment that involves changes and psychological and social adaptations in women's lives ${ }^{(8)}$. Among the anxiety disorders, state anxiety is considered a transient emotional state, while trait anxiety is related to relatively stable individual characteristics in the propensity to anxiety ${ }^{(9)}$. In this context, comorbidities are common, and women with anxiety symptoms are three times more likely to have PTSD ${ }^{(10)}$, another anxiety disorder in which the person relives a traumatic event repeatedly when exposed to internal or external cues that symbolize or recall such events. Mental disorders during pregnancy are common, highly prevalent and, yet, poorly diagnosed. Multiple risk factors are involved in the genesis of these disorders, and IPV is a common predictor for the occurrence of trait and state anxiety and PTSD, during pregnancy.

Therefore, it is necessary to develop strategies and interventions to prevent both the obvious consequences of abuse and the impact on the mental health of women. However, studies conducted in Latin America aimed at investigating the relationship between posttraumatic stress disorder, trait and state anxiety, and intimate partner violence, all occurring during pregnancy, were not found in the national and international scientific literature.

Thus, this study aimed to identify the relationship between posttraumatic stress disorder, trait and state anxiety, and intimate partner violence, during pregnancy.

\section{Method}

This is an observational study with cross-sectional design, developed in the clinic of the Ribeirão Preto Woman Health Reference Center - Mater (CRSMRPMATER), in the city of Ribeirão Preto, São Paulo, Brazil.

Ribeirão Preto is a regional reference in health for 26 municipalities that make up the 13th Regional Health Department (DRS XIII) of the state of São Paulo, covering an estimated population of 1,300,000 inhabitants. In this context, CRSMRP-MATER is a regional reference for gynecological cases of medium complexity and carries out about a third of the births of low and medium risk of the Unified Health System (SUS) in the city. In addition, the clinic serves, daily, about 25 new cases of prenatal care, coming from different regions of Ribeirão Preto and other cities in the DRS XIII area. CRSMRPMATER is integrated with the "Birth Project", created in 1999 by the Municipal Department of Health of Ribeirão Preto in order to overcome the difficulties of access to maternity hospitals. The project defends that prenatal monitoring is conducted in the primary care of Ribeirão Preto and the municipalities that compose the DRS XIII until the 36th week of pregnancy and, thereafter, in public hospitals until the end of the pregnancychildbirth cycle. Thus, the actions to be developed in the CRSMRP-MATER are: i. prenatal care of pregnant 
women referred from primary care, from the 36th week of pregnancy, according to regionalization; ii. guaranteed admission of parturient women and referral to other maternity if there are no available beds; and iii. care for obstetric emergencies. The hospital referral enabled the integration between the prenatal, delivery and postpartum care and allowed pregnant women to know where they will give birth and the moment they will be evaluated by the hospital staff.

The reference population of the study consisted of all pregnant women, in the third trimester of pregnancy, in prenatal care monitoring in the CRSMRP-MATER clinic between May 2012 and May 2013. Inclusion criteria were: pregnant women aged between 15 and 49 years and who had or had had a relationship with an intimate partner in the current pregnancy, regardless of cohabitation. The sample was obtained by systematic random sampling procedure, with constant sampling intervals of four units. Based on a finite population of 1,600 pregnant women, in a prevalence of $20.0 \%$ and a precision of $4.0 \%$ for an estimated $95.0 \%$ confidence, the sample needed for the study was of 358 pregnant women. Estimating $15.0 \%$ of loss in the sampling grid, the expected number of attempted interviews was 422. Importantly, the losses in the sampling grid were due to refusals to participate, to non-attendance of pregnant women to appointments, and to no eligibility to participate in the study, which contributed to the fact that the collection of data took one year.

Data were collected on the first prenatal consultation of pregnant women in the service, at 36 weeks of gestation, in a private room available exclusively to researchers and with no companions. The interviews took between 15 and 20 minutes and were conducted by four previously trained interviewers. At that time, the eligible pregnant women, according to the sampling interval and the inclusion criteria, were invited to participate in the study after receiving clarifications on its nature and objectives.

To collect the data, four instruments were used. The sociodemographic, behavioral, and obstetric characterization of the participants was obtained through an instrument elaborated by the researchers, based on their previous experiences and collated with national and international scientific literature. The final version was submitted to content and appearance validation by three expert judges in the area. Through this instrument, the following variables were investigated: age, marital status, formal education, occupation, family income, habitual smoking, alcohol consumption, and illicit drug use during the current pregnancy, number of pregnancies, parity, prior abortion(s), prior preterm delivery(s), number of living children, prior fetal death(s), and prior early neonatal death(s).

The prevalence of posttraumatic stress disorder during pregnancy was identified through the Posttraumatic Stress Disorder Checklist - Civilian Version (PCL-C), an instrument validated in Brazil, self-administered, of public domain, and based on the DSM-IV-TR diagnostic criteria for PTSD. This instrument does not enable a definitive diagnosis of PTSD, as it provides an indication of the presence of symptoms suggestive of the disorder. During application, the individual must answer 17 items that measure how much disturbed one has been, in the last month, due to problems and complaints related to stressful life experiences. Each item has a Likert-like severity scale ranging from one to five points. The indication of PTSD is confirmed when the person experienced, witnessed, or was confronted by a traumatic event (diagnostic criterion A for PTSD, according to the DSM-IV-TR) and shows a clinically significant symptom of diagnostic criterion B (persistent reliving - measured by the first five items), three symptoms of diagnostic criterion C (avoidant behavior or emotional numbness items 6 to 12), and two symptoms of diagnostic criterion D (hyperexcitability - items 13 to 17). The instrument considers as a clinically significant symptom a score greater or equal to three, in one of the 17 items $^{(11)}$. Thus, this instrument identifies whether a person has or not the indication of PTSD. The internal consistency of the answers of the study participants to the PCL-C instrument, measured by Cronbach's alpha coefficient, was 0.93. For the diagnostic criteria B, C, and D, measured in the instrument, we found Cronbach's alpha values of $0.88,0.85$, and 0.82 , respectively.

The State-Trait Anxiety Inventory (STAI) was used in this study to estimate the levels of symptoms of trait and trace anxiety of participants, through scores, as it does not allow the diagnosis of anxiety. It is a publicdomain tool, validated in Brazil, and consists of two self-report scales (STAI-Trait and STAI-State). Each scale contains 20 items with four alternatives, whose values range from one to four points. The sum of points of each question makes a score of at least 20 and at most 80 , in each scale. The higher the score the greater the chance of an individual having anxiety symptoms. STAI-State assesses how the individual feels at the time of interview, while STAI-Trait assesses how the person usually feels ${ }^{(12)}$. Internal consistencies of the state 
anxiety and trait anxiety scales, measured by Cronbach's alpha coefficient, were 0.87 and 0.86 , respectively.

PCL-C and STAI can be applied by health professionals without experience in the mental health field. In Brazil, given the context of health services, this situation is particularly important, since the detection of probable cases will optimize their referral to specialized professionals for the conduct of clinical diagnosis.

The issues related to intimate partner violence were adapted for use during pregnancy, based on the Brazilian version of the instrument developed for the World Health Organization Multi-country Study on Women's Health and Domestic Violence, which addresses the psychological, physical, and sexual IPV $^{(13)}$. Participants were asked about their experiences of specific acts of psychological IPV (insults, humiliation, depreciation, scares, intimidation, and threats), physical IPV (slapping, shoving, forceful pulls, shaking, punches, kicks, dragging, beatings, strangling, burns and use of firearms or cold weapons) and sexual IPV (being forced, physically, to have sex, having sex due to fear of the partner, and being forced into a degrading or humiliating sexual practice), during the current pregnancy. For analysis purposes, the variable "general violence" was used when the participant suffered any of these three types of violent acts. Internal consistencies of the blocks of psychological, physical, and sexual IPVs, measured by Cronbach's alpha coefficient, were $0.69,0.93$, and 0.89 , respectively.

Statistical analysis was performed using Statistical Package for Social Sciences (SPSS) software version 21.0 for Mac. In the univariate analysis, qualitative variables were presented as distribution of absolute frequencies ( $n$ ) and relative frequencies (\%); and for quantitative variables, mean and median values were calculated (central tendency measures), standard deviations, and minimum and maximum values (variation ranges). To identify the association between intimate partner violence and indication of posttraumatic stress disorder during the current pregnancy, we built a multiple logistic regression model, calculating adjusted Prevalence Odds Ratios (POR) to verify the associations between the main predictor variable (general IPV) and the outcome variable (indication of PTSD). We included in the model the main predictor variable and the predictor variables, of adjustment with theoretical relevance for the analysis, potential confounding factors: marital status, planned pregnancy, licit or illicit drugs use by the participant, and family income. To identify the relationship between intimate partner violence and scores for symptoms of trait anxiety and state anxiety, during pregnancy, we built two models of multiple linear regression, one for state anxiety and one for trait anxiety. We included in the models the Main Predictor Variable (general IPV) and the predictors of adjustment with theoretical relevance for the analysis of potential confounding factors: marital status, age, education, and family income. For all tests, we considered a Confidence Interval (CI) of $95.0 \%$ and an a significance level of $5.0 \%$.

The project was approved by the Research Commission of the CRSMRP-MATER and by the Research Ethics Committee (REC) of the Ribeirão Preto School of Nursing, University of São Paulo, under Protocol No. $1377 / 2011$. Interviews were conducted after the signing of the Informed Consent (IC), a signed copy being left with the researcher and the other with the informant. For underage participants, we used the Consent Agreement, as the respective legal representative could be the aggressor and have interest in not authorizing participation. At the end of the interview, all informants received leaflets listing the protection services for women in situations of violence in Ribeirão Preto and region. Moreover, the assistant physician of the clinic and the CRSMRP-MATER psychology service were informed when 12 pregnant women requested immediate assistance and when the interviewers identified women in IPV situations and/or anxiety symptoms and/or indication of PTSD.

\section{Results}

Exposure to IPV during pregnancy increased the chances of the women participating in this study presenting indication of PTSD and greater scores for symptoms of trait and state anxiety.

The prevalence of IPV, during the current pregnancy, was $17.6 \%$ (63). Among the pregnant women that suffered IPV, 60 (95.2\%) were in situation of psychological violence, 23 (36.5\%) of physical violence, and $1(1.6 \%)$ of sexual violence (Table 1$)$.

Among the 358 women, 61 (17.0\%) had indication of PTSD. Of these, 24 (39.3\%) were victims of IPV, during the current pregnancy. The mean STAITrait score of pregnant women was 39.1 (Standard Deviation, $S D=10.0$ ) points and ranged between 20 and 75 . The mean score in the state anxiety scale was $42.5(S D=9.8)$ points and ranged between 23 and 75 .

The mean age of the 358 pregnant women was 25.0 years $(S D=6.3)$ and ranged between 15 and 43 years. 
Most considered themselves as non-white (62.3\%), had a religion $(79.3 \%)$, cohabited with an intimate partner $(80.4 \%)$, and had no paid occupation (57.3\%), with average monthly family income of 2.6 monthly minimum wages $(S D=1.5)$. The average formal education of women was 9.5 years of schooling $(S D=2.4)$ and ranged between 1 and 17 years. Most women did not smoke (93.3\%), did not consume alcoholic beverages (88.3\%), and did not use illicit drugs (99.2\%), during the current pregnancy (Table 1).

Table 1 - Prevalence of PTSD and scores for symptoms of trait and state anxiety according to sociodemographic, behavioral and obstetric variables of pregnant women undergoing prenatal care in the CRSMRP-MATER clinic. Ribeirão Preto, SP, Brazil, 2013

\begin{tabular}{|c|c|c|c|c|c|c|}
\hline \multirow{2}{*}{ Variables } & \multirow{2}{*}{$\mathbf{n}$} & \multirow{2}{*}{$\%$} & \multicolumn{2}{|c|}{ PTSD* } & \multirow{2}{*}{$\begin{array}{l}\text { Trait anxiety } \\
\text { Score }\end{array}$} & \multirow{2}{*}{$\begin{array}{l}\text { State anxiety } \\
\text { Score }\end{array}$} \\
\hline & & & $\mathbf{n}$ & $\%$ & & \\
\hline \multicolumn{7}{|l|}{ Age group (complete years) } \\
\hline $15-19$ & 78 & 21.8 & 15 & 19.2 & 41.6 & 43.6 \\
\hline $20-29$ & 186 & 52.0 & 33 & 17.7 & 39.0 & 41.7 \\
\hline $30-39$ & 88 & 24.6 & 13 & 14.8 & 37.4 & 43.2 \\
\hline $40-49$ & 6 & 1.6 & 0 & 0.0 & 34.0 & 41.5 \\
\hline \multicolumn{7}{|l|}{ Self-declared skin color } \\
\hline Non-white & 135 & 37.7 & 44 & 32.6 & 40.0 & 43.4 \\
\hline White & 223 & 62.3 & 17 & 7.6 & 37.8 & 40.9 \\
\hline \multicolumn{7}{|l|}{ Formal Education (years) } \\
\hline $1-8$ & 121 & 33.8 & 26 & 21.5 & 42.0 & 44.9 \\
\hline $9-11$ & 196 & 54.7 & 33 & 16.8 & 38.2 & 41.1 \\
\hline 12 or more & 40 & 11.2 & 2 & 5.0 & 34.8 & 41.5 \\
\hline Does not know & 1 & 0.3 & 0 & 0.0 & 41.0 & 46.0 \\
\hline \multicolumn{7}{|l|}{ Religion } \\
\hline Yes & 284 & 79.3 & 52 & 18.3 & 38.8 & 42.3 \\
\hline No & 74 & 20.7 & 9 & 12.2 & 40.2 & 43.0 \\
\hline \multicolumn{7}{|l|}{ Marital status } \\
\hline Cohabiting & 288 & 80.4 & 49 & 17.0 & 38.7 & 42.0 \\
\hline Has a partner, not cohabiting & 45 & 12.6 & 3 & 6.7 & 39.5 & 42.7 \\
\hline $\begin{array}{l}\text { Had a partner during } \\
\text { pregnancy, not anymore }\end{array}$ & 25 & 7.0 & 9 & 36.0 & 42.8 & 47.2 \\
\hline \multicolumn{7}{|l|}{ Paid occupation } \\
\hline Yes & 153 & 42.7 & 24 & 15.7 & 38.7 & 42.4 \\
\hline No & 205 & 57.3 & 37 & 18.0 & 39.4 & 42.5 \\
\hline \multicolumn{7}{|l|}{$\begin{array}{l}\text { Monthly family income }{ }^{\dagger} \text { (in } \\
\text { monthly minimum wages) }\end{array}$} \\
\hline One or less & 44 & 12.3 & 12 & 27.3 & 41.0 & 43.1 \\
\hline Two-three & 199 & 55.6 & 26 & 13.0 & 38.6 & 42.1 \\
\hline Four or more & 54 & 15.1 & 9 & 16.7 & 36.0 & 41.9 \\
\hline Does not know & 61 & 17.0 & 14 & 22.9 & 41.7 & 43.4 \\
\hline \multicolumn{7}{|l|}{ Habitual smoking } \\
\hline Yes & 24 & 6.7 & 2 & 8.3 & 39.4 & 43.4 \\
\hline No & 334 & 93.3 & 59 & 17.7 & 39.1 & 42.4 \\
\hline \multicolumn{7}{|l|}{ Alcohol consumption } \\
\hline Yes & 42 & 11.7 & 9 & 21.4 & 41.7 & 44.9 \\
\hline No & 316 & 88.3 & 52 & 16.4 & 38.8 & 42.1 \\
\hline \multicolumn{7}{|l|}{ Illicit drug use } \\
\hline Yes & 3 & 0.8 & 0 & 0.0 & 43.0 & 48.0 \\
\hline No & 355 & 99.2 & 61 & 17.2 & 39.1 & 42.4 \\
\hline \multicolumn{7}{|l|}{ Number of pregnancies } \\
\hline Primigravida & 143 & 39.9 & 21 & 14.7 & 39.0 & 41.6 \\
\hline Multigravida & 215 & 60.1 & 40 & 18.6 & 39.2 & 43.0 \\
\hline \multicolumn{7}{|l|}{ Parity } \\
\hline Nullipara & 158 & 44.2 & 22 & 13.9 & 38.9 & 41.7 \\
\hline Primipara & 110 & 30.7 & 22 & 20.0 & 39.2 & 43.2 \\
\hline Multipara & 90 & 25.1 & 17 & 18.9 & 39.5 & 42.9 \\
\hline
\end{tabular}


Table 1 - (continuation)

\begin{tabular}{|c|c|c|c|c|c|c|}
\hline \multirow{2}{*}{ Variables } & \multirow{2}{*}{$\mathbf{n}$} & \multirow{2}{*}{$\%$} & \multicolumn{2}{|c|}{ PTSD* } & \multirow{2}{*}{$\begin{array}{l}\text { Trait anxiety } \\
\text { Score }\end{array}$} & \multirow{2}{*}{$\begin{array}{l}\text { State anxiety } \\
\text { Score }\end{array}$} \\
\hline & & & $n$ & $\%$ & & \\
\hline \multicolumn{7}{|l|}{ Living children } \\
\hline Yes & 198 & 55.3 & 39 & 19.7 & 39.4 & 43.2 \\
\hline No & 160 & 44.7 & 22 & 13.7 & 38.8 & 41.6 \\
\hline \multicolumn{7}{|l|}{ Planned pregnancy } \\
\hline Yes & 134 & 37.4 & 27 & 20.1 & 38.3 & 40.6 \\
\hline No & 224 & 62.6 & 34 & 15.2 & 39.6 & 43.6 \\
\hline \multicolumn{7}{|l|}{$\mathrm{IPV} \mathrm{P}^{\ddagger}$ during pregnancy } \\
\hline Yes & 63 & 17.6 & 24 & 38.1 & 48.0 & 48.4 \\
\hline No & 295 & 82.4 & 37 & 12.5 & 37.2 & 41.2 \\
\hline Total & 358 & 100 & 61 & - & - & - \\
\hline
\end{tabular}

* Posttraumatic stress disorder.

† The reference monthly minimum wage for 2012 was BRL 622 and, for 2013, it was BRL 678 .

$\ddagger$ Intimate Partner Violence

The study sample was characterized by multigravidas $(60.1 \%)$ and nulliparas (44.2\%). The majority (198 $55.3 \%$ ) of the pregnant women had living children. The average number of living children was $1.7(\mathrm{SD}=1.0)$ and ranged between 1 and 6 . The current pregnancy had not been planned by $62.6 \%$ of the women (Table 1 ).

IPV, occurred during the current pregnancy, was associated with the indication for diagnosis of PTSD, even after adjusting for potential confounding variables, defined in the national and international scientific literature $\left(P O R_{\text {adjusted }}=5.25 ; C_{95.0 \%} 2.53-10.93\right.$; $\mathrm{p}<0.001$ ). The odds of pregnant women in IPV situations, in the current pregnancy, presenting indication of PTSD diagnosis were 5.25 times higher than women who were not victims of their partners in the same period, even after adjusting for marital status, for the use of licit or illicit drugs, during the current pregnancy, for age, and for monthly family income (Table 2 ).

Table 2 - Association between intimate partner violence, occurred during the current pregnancy, and indication of posttraumatic stress disorder, in a multiple logistic regression model. Ribeirão Preto, Brazil, SP, 2013

\begin{tabular}{|c|c|c|c|c|c|c|c|}
\hline \multirow{3}{*}{ Variables } & \multicolumn{7}{|c|}{ Posttraumatic stress disorder } \\
\hline & \multicolumn{2}{|c|}{ Yes } & \multicolumn{2}{|c|}{ No } & \multirow{2}{*}{$\begin{array}{c}\text { POR }_{\text {crude }} \\
\left(\mathrm{Cl}_{95.0 \%}\right)\end{array}$} & \multirow{2}{*}{$\begin{array}{l}\text { POR }_{\text {adjusted }} \\
\left(\mathrm{Cl}_{95.0 \%}\right)\end{array}$} & \multirow{2}{*}{$\mathbf{p}^{\dagger}$} \\
\hline & $\mathbf{n}$ & $\%$ & $\mathbf{n}$ & $\%$ & & & \\
\hline \multicolumn{8}{|l|}{ Intimate partner violence } \\
\hline Yes & 24 & 38.1 & 39 & 61.9 & $4.29(2.3-7.9)$ & $5.25(2.5-10.9)$ & $<0.001$ \\
\hline No & 37 & 12.5 & 258 & 87.5 & & & \\
\hline \multicolumn{8}{|l|}{ Marital status } \\
\hline Cohabiting & 49 & 17.0 & 239 & 83.0 & $0.99(0.5-1.9)$ & $1.02(0.4-2.4)$ & 0.97 \\
\hline Not cohabiting & 12 & 17.1 & 58 & 82.9 & & & \\
\hline \multicolumn{8}{|l|}{ Drug use } \\
\hline Yes & 10 & 16.9 & 49 & 83.1 & $0.99(0.5-2.1)$ & $0.55(0.2-1.5)$ & 0.25 \\
\hline No & 51 & 17.1 & 248 & 82.9 & & & \\
\hline Pregnant woman age & - & - & - & - & - & $0.98(0.9-1.0)$ & 0.39 \\
\hline Family income ${ }^{\ddagger}$ & - & - & - & - & - & $0.92(0.7-1.2)$ & 0.49 \\
\hline
\end{tabular}

* Prevalence odds ratio.

+ P-value for the Wald chi-square test.

‡ The reference monthly minimum wage for 2012 was BRL 622 and, for 2013, it was BRL 678 .

After adjusting for the potential confounding variables, previously recognized in the national and international scientific literature, such as marital status, age, education, and family income, women in IPV situations, in the current pregnancy, had higher scores for symptoms of trait anxiety (Beta=0.38; $\mathrm{p}<0.001)$ and state anxiety (Beta=0.25; $\mathrm{p}<0.001$ ) than those who had not suffered such violence (Table 3).

Furthermore, in this model, in addition to IPV, the variables age $(p=0.01)$ and education $(p=0.001)$ were statistically significant predictors of the score for 
symptoms of trait anxiety. Thus, the higher the age (Beta $=-0.14)$ and education level (Beta=-0.18), the lower the score for symptoms of trait anxiety. Similarly, in relation to the score for symptoms of state anxiety, in addition to general IPV, the variable education level also characterized as a statistically significant predictor $(p=0.003)$. Therefore, the higher the education level of the pregnant women, the lower the score for symptoms of state anxiety (Beta $=-0.18$ ) (Table 3).

Table 3 - Relationship between intimate partner violence, occurred during the current pregnancy, and scores for symptoms of trait and state anxiety, in multiple linear regression models. Ribeirão Preto, SP, Brazil, in 2013

\begin{tabular}{|c|c|c|}
\hline \multirow{3}{*}{ Variables } & \multicolumn{2}{|c|}{ TAl score for symptoms of trait and state anxiety* } \\
\hline & Beta & $\mathbf{p}^{\dagger}$ \\
\hline & \multicolumn{2}{|c|}{ STAI-Trait } \\
\hline Intimate partner violence $(\mathrm{yes}=1 ; \mathrm{no}=0)$ & 0.38 & $<0.001$ \\
\hline Marital status (cohabiting $=1$; not cohabiting $=0$ ) & -0.01 & 0.83 \\
\hline Age & -0.14 & 0.01 \\
\hline Education & -0.18 & 0.001 \\
\hline \multirow[t]{2}{*}{ Monthly family income ${ }^{\ddagger}$} & -0.01 & 0.86 \\
\hline & \multicolumn{2}{|c|}{ STAI-State } \\
\hline Intimate partner violence $(\mathrm{yes}=1 ; \mathrm{no}=0)$ & 0.25 & $<0.001$ \\
\hline Marital status (cohabiting $=1$; not cohabiting $=0$ ) & -0.06 & 0.26 \\
\hline Age & -0.01 & 0.84 \\
\hline Education & -0.18 & 0.003 \\
\hline Monthly family income $e^{\ddagger}$ & 0.05 & 0.39 \\
\hline
\end{tabular}

* State-Trait Anxiety Inventory.

+ P-value for the student $t$ test.

₹ The reference monthly minimum wage for 2012 was BRL 622 and, for 2013, it was BRL 678.

\section{Discussion}

The results of this study indicate that intimate partner violence, occurred during pregnancy is a significant and independent predictor of indication of posttraumatic stress disorder in pregnant women. This result is consistent with data from an investigation conducted in the United States ${ }^{(14)}$, in which pregnant women with indication of PTSD reported having been victims of physical or psychological IPV during pregnancy. It was also evident that the violence perpetrated by an intimate partner is the leading independent predictor of symptoms of trait and state anxiety during pregnancy, which corroborates the findings of a research conducted in Bangladesh, in which pregnant women in IPV situations, during the current pregnancy, had higher scores for trait anxiety symptoms ${ }^{(6)}$. Authors of studies carried out in countries such as South Africa(15) and Portugal(16) reported that IPV during pregnancy has been identified as an independent risk factor associated with the occurrence of generalized anxiety symptoms in pregnant women.

Considering the findings that schooling is also configured as a predictor of the scores of the participants in the STAI-state and STAI-Trait, and that age was characterized as a risk factor for the genesis of trait anxiety symptoms, it becomes necessary to focus on the social risk factors, such as age and education, for the prevention of anxiety. These two factors, associated with IPV, can make women less able to face the new conditions imposed by the pregnancy, thus increasing their predisposition to the development of anxiety symptoms ${ }^{(17)}$.

The observed prevalence of intimate partner violence during pregnancy, $17.6 \%$, is similar to those described for other Latin American countries and other locations in Brazil (from 8.0 to $43.0 \%)^{(4,18,19)}$. The figures found in the literature and in this study suggest that IPV, during pregnancy, is more common than some maternal pathologies recognized and tracked during prenatal care, such as preeclampsia and gestational diabetes ${ }^{(3)}$.

Given the complexity of IPV, its reflects in the mental health of women during pregnancy, and the fact that such violence is associated with clinically identifiable risk and protection factors, actions tackling IPV should be incorporated by health professionals into the care that is routinely provided to women during the prenatal period, in order to maintain the biopsychosocial health and wellbeing of mother and child. There is the important need 
to identify the factors that can increase or decrease the risk of occurrence of this problem with a view to primary prevention. Thus, since it is a problem rooted in most cultures, IPV has a multifactorial origin and is determined by individual, family, community and sociocultural factors, such as: poor socioeconomic conditions, low educational level, not living with spouse in countries where separation is a right, experience of abuse in childhood, violence in the family or between parents, early age at first intercourse, financial empowerment of women, alcohol abuse, and multiparity, among others $^{(20-21)}$.

Since the 1980s, the attention given to addressing violence against women in Brazil increased. In 1985, the ending of the Women's Decade declared by the United Nations (UN) opened the first Police Specializing in Assisting Women (DEAM) and created the National Council for Women's Rights (CNDM). In the following year, the first shelter of the country geared to women in situations of risk and violence was created. In 1998, the Ministry of Health proposed a Technical Standard for the prevention and treatment of injuries resulting from sexual violence, which ensured the care of victims in health services, in order to prevent sexually transmitted infections and unwanted pregnancy ${ }^{(1)}$.

From 1985 to 2002, public policies for combating violence against women in Brazil focused on isolated actions of public security and social assistance, with emphasis on DEAMs and in Shelters. Since 2003, these policies have been extended and integrated actions such as: improvement of legislation, creation of treatment protocols, stimulus for the formation of service networks, support to the preparation of educational and cultural projects for prevention of violence, and increase of access to justice and public security. Thus, in 2003, Law $10.778 / 03$ was enacted, establishing the Compulsory Notification of cases of violence against women served in public or private health services. In 2006, the Maria da Penha Law (Law 11.340/06) was enacted, which created mechanisms to restrain domestic and family violence against women, and in line with Article 226 $\S 8$ of the Federal Constitution, with the Convention on the Elimination of all Forms of Discrimination against Women (CEDAW) of the United Nations (1981) and the Convention of Belém do Pará. Currently, the National Policy to Fight Violence Against Women agenda is the adoption of comprehensive and intersectoral strategies to prevent and combat violence, to assist and guarantee the rights of women, which is consolidated through agreements between the federal, state and municipal governments, reaffirmed in the National Pact to Combat Violence against Women ${ }^{(1)}$.

However, even with the proposal to develop educational and cultural activities to promote women's empowerment and deconstruct gender inequality, bringing this understanding to social spaces where it is constructed and legitimized(21), the lines of actions defined in the policies, plans and national pacts to tackle violence against women emphasize secondary and tertiary prevention strategies, focusing on treatment and support to victims ${ }^{(1)}$.

Furthermore, even considering a reality in which most of the human and financial resources is intended for immediate and/or long-term tackling of the consequences of violence, the problem still goes unnoticed and silent by health services, often because of personal reasons of the victims and/or lack of training of professionals ${ }^{(21)}$. Therefore, the construction of a new approach to the health/disease process is necessary, which considers the social, economic, cultural and emotional context of women, as well as the establishment of new bases for the relationship between the various subjects involved in health promotion.

The impasses resulting from this traditional way of "producing health" are challenging and a critical point to overcome this situation is the training of human resources in health, as the training profile of these professionals is still guided by the logic of fragmented, vertical, individual and curative care(22). Nursing professionals should be trained to conduct an interpersonal approach that involves the ethical and humanistic aspects that underlie the targeted assistance to victims of violence, which focuses on the strengthening and empowerment of women and not only on relief of pain and treatment of symptoms and diseases resulting from the abuse suffered. After identification, they must be committed to proper registration, to teamwork, and to bring the case to the existing intersectoral network, ensuring the protection of legal, human, sexual and reproductive rights as well as the principles of non-judgment and respect for women's decisions, with an emphasis on communication and on assistance projects negotiated and built in partnership. Therefore, the transformation of values related to social conformations of gender is urgent, and the new values must be incorporated by health professionals in their assistance, in daily services $^{(23)}$.

Pregnancy is a period in which the woman is in frequent contact with health professionals and, therefore, more likely to reveal their situation of violence 
and their psychiatric symptoms. Professionals, especially the nursing staff, should pay attention, in their overall assessment, to the occurrence of symptoms indicative of mental disorders in this period of women's lives, as well as relevant risk factors such as intimate partner violence, which can be effected by the adoption of instruments such as those used in this study. Moreover, they should adopt strategies and mechanisms to refer women with such indication to appropriate evaluation and support ${ }^{(6)}$. Detection of cases of IPV during pregnancy contributes to the externalization of feelings by women and, therefore, ensures the escape from their emotional and social isolation(24).

This is the first study that reveals that intimate partner violence during pregnancy is the main factor associated with symptoms of trait and state anxiety, as well as indication of posttraumatic stress disorder among Brazilian and Latin American women(25). In addition, the observation that IPV, occurred during pregnancy, prevailed over the other risk factors for trait and state anxiety and indication of PTSD, recognized in national and international scientific literature, suggests that interventions aimed at these predictors may not be as effective for the prevention of adverse effects on the mental health of women. Thus, it is expected that the results obtained can fill gaps in this area and advance the frontiers of knowledge towards the sensitization and awareness of policy makers and health care providers as to the seriousness of the problem and how it affects women's health.

\section{Study limitations}

Some limitations of the study should be mentioned. First, instruments were used to screen the symptoms of the mental disorders investigated and not diagnostic interviews conducted by professionals, which may have overestimated the prevalence of the indication of posttraumatic stress disorder and of symptom scores for trait and state anxiety. Second, the data obtained refer to the population of low-risk pregnant women that are clients of the Unified Health System (SUS) and, therefore, may differ and limit the generalizability to other populations. Third, despite the care taken by interviewers in order to bond with the participants, the prevalence of violence may have been underestimated due to embarrassment or fear of the pregnant women in relation to disclosing this information. However, an internationally recognized instrument was used, which utilizes a judgment-free approach regarding violence.
Four, the prevalence of IPV may also have been underestimated, as the interview was conducted at week 36 and the pregnant woman may - still, until the end of pregnancy - have been victim of violence not detected by the study.

\section{Conclusion}

Nursing professionals involved in maternity care should target the intimate partner violence and must incorporate, in their practice, strategies for building trust and bond, providing learning opportunities and access to social, institutional, and intersectoral assistance. The creation, implementation, and monitoring of multisectoral action plans to fight violence perpetrated by partners will boost the development, implementation and evaluation of programs aimed at primary prevention of such violence, as well as at raising awareness of the legal and judicial systems as for the needs of women who are victims of violence. This approach will contribute to the promotion of gender equality and of the human rights of women and, consequently, to identify mental disorders during pregnancy.

\section{References}

1. Secretaria Nacional de Enfrentamento à Violência contra as Mulheres (BR). Secretaria de Políticas para as Mulheres. Política Nacional de Enfrentamento à Violência contra as Mulheres. Brasília: Presidência da República; 2011.

2. Taillieu TL, Brownridge DA. Violence against pregnant women: prevalence, patterns, risk factors, theories, and directions for future research. Aggress Violent Behav. 2010 Jan- Feb;15(1):14-35.

3. Devries KM, Kishor S, Johnson H, Stöckl H, Bacchus LJ, Garcia-Moreno $C$, et al. Intimate partner violence during pregnancy: analysis of prevalence data from 19 countries. Reprod Health Matters. 2010 Nov;18(36):158-70.

4. Han A, Stewart DE. Maternal and fetal outcomes of intimate partner violence associated with pregnancy in the Latin American and Caribbean region. Int J Gynaecol Obstet. 2014 Jan;124(1):6-11.

5. Ellis KK, Chang C, Bhandari S, Ball K, Geden E, Everett KD, et al. Rural mothers experiencing the stress of intimate partner violence or not: their newborn health concerns. J Midwifery Womens Health. 2008 NovDec;53(6):556-62.

6. Nasreen $\mathrm{HE}$, Kabir ZN, Forsell $\mathrm{Y}$, Edhborg $\mathrm{M}$. Prevalence and associated factors of depressive and 
anxiety symptoms during pregnancy: a population based study in rural Bangladesh. BMC Women's Health. 2011 Jun; 11:22.

7. Onoye JM, Shafer LA, Goebert DA, Morland LA, Matsu $C R$, Hamagami F. Changes in PTSD symptomatology and mental health during pregnancy and postpartum. Arch Womens Ment Health. 2013;16:453-63.

8. Gourounti K, Lykeridou K, Taskou C, Kafetsios K, Sandall J. A survey of worries of pregnant women: Reliability and validity of the Greek version of the Cambridge Worry Scale. Midwifery. 2012;28(6):746-53.

9. Cattel RB, Scheier IH. The meaning and measurement of neuroticism and anxiety. New York (NY): Ronald Press; 1961.

10. Cook CAL, Flick LH, Homan SM, Campbell C, McSweeney M, Gallagher ME. Posttraumatic stress disorder in pregnancy: prevalence, risk factors, and treatment. Obstet Gynecol. 2004 Apr;103(4):710-7.

11. Passos RBF, Figueira I, Mendlowicz MV, Moraes $\mathrm{CL}$, Coutinho ESF. Exploratory factors analysis of the Brazilian version of the Post-Traumatic Stress Disorder Checklist: civilian version (PCL-C). Rev Bras Psiquiatr. 2012 Jun;34(2): 155-61.

12. Biaggio $A M B$, Natalicio L. Manual para o Inventário de Ansiedade Traço-Estado (IDATE). Rio de Janeiro (RJ): Centro Editor de Psicologia Aplicada-CEPA; 1979.

13. Schraiber LB, Latorre MRDO, França I Jr, Segri NJ, D'Oliveira AFPL. Validity of the WHO VAW STUDY instrument for estimating gender-based violence against women. Rev Saúde Pública. 2010;44(4):658-66.

14. Huth-Bocks AC, Krause K, Ahlfs-Dunn S, Gallagher E, Scott S. Relational trauma and posttraumatic stress symptoms among pregnant women. Psychodyn Psychiatr. 2013;41(2):277-301.

15. Groves AK, Kagee A, Maman S, Moodley D, Rouse P. Associations between intimate partner violence and emotional distress among pregnant women in Durban, South Africa. J Interpers Violence. 2012 May;27(7):1341-56.

16. Almeida $\mathrm{CP}$, Cunha FF, Pires EP, Sá E. Common mental disorders in pregnancy in the context of interpartner violence. J Psychiatr Ment Health Nurs. 2013 Apr;20(5):419-25.

17. Bödecs T, Szilágyi E, Cholnoky P, Sándor J, Gonda $X$, Rihmer $Z$, et al. Prevalence and psychosocial background of anxiety and depression emerging during the first trimester of pregnancy: data from a Hungarian population-based sample. Psychiatr Danub. 2013 Dec;25(4):352-8.
18. Ludermir AB, Lewis $G$, Valongueiro SA, de Araújo TV, Araya R. Violence against women by their intimate partner during pregnancy and postnatal depression: a prospective cohort study. Lancet. 2010 Sep;376(9744):903-10.

19. Santos AG, Nery IS, Rodrigues DC, Sousa A. Violence against pregnant women in special police departments for assistance to women in Teresina-PI. Rev Rene. 2010 dez;11(num.esp):109-16.

20. d'Oliveira AF, Schraiber LB, França-Junior I, Ludermir $A B$, Portella AP, Diniz CS, et al. Factors associated with intimate partner violence against Brazilian women. Rev Saúde Pública. 2009 Apr;43(2):299-311.

21. Guedes RN, Silva ATMC, Fonseca RMGS. The violence of gender and health-disease process of women. Esc Anna Nery. 2009 Jul-Sep;13(3):625-31.

22. Salcedo-Barrientos DM, Miura PO, Macedo VD, Egry EY. How do primary health care professionals deal with pregnant women who are victims of domestic violence? Rev. Latino-Am. Enfermagem. 2014;22(3):448-53.

23. d'Oliveira AF, Schraiber LB, Hanada $H$, Durand J. Comprehensive health (care) services to women in gender violence situation: an alternative to primary health care. Ciênc Saúde Coletiva. 2009 Jul; 14(4): 1037-50.

24. Crempien RC, Rojas G, Cumsille P, Oda MC. Domestic violence during pregnancy and mental health: exploratory study in primary health centers in Peñalolén. ISRN Obstet Gynecol. 2011.

25. Fonseca-Machado MO, Alves LC, Freitas PS, Monteiro JCS, Gomes-Sponholz F. Mental health of women who suffer intimate partner violence during pregnancy. Invest Educ Enferm. 2014; 32(2):291-305. 